\title{
Teores de nitrato e amônio no solo em função de culturas de entressafra da soja e adubação nitrogenada
}

\author{
Anderson Hideo Yokoyama ${ }^{1}$, Alvadi Antonio Balbinot Junior ${ }^{2}$, Ricardo Henrique Ribeiro ${ }^{3}$, Julio Cezar \\ Franchini ${ }^{2}$, Henrique Debiasi ${ }^{2}$, Claudemir Zucareli ${ }^{1}$ \\ ${ }^{1}$ Universidade Estadual de Londrina, Programa de Pós Graduação em Agronomia, Londrina, PR. ${ }^{2}$ Embrapa Soja, \\ Londrina, PR. E-mail: alvadi.balbinot@embrapa.br. ${ }^{3}$ Universidade Federal de Santa Catarina, Curitibanos, SC.
}

\begin{abstract}
Resumo
O objetivo desse trabalho foi avaliar os teores de nitrato e amônio no solo na entressafra e na safra de soja em função de culturas de entressafra e fertilização com $\mathrm{N}$ mineral na soja. $\mathrm{O}$ delineamento experimental foi de blocos completos casualizados, com cinco repetições e em esquema de parcelas subdivididas. Nas parcelas foram alocados seis tratamentos de entressafra: pousio, milho segunda safra com 0 ou $80 \mathrm{~kg}$ de N $\mathrm{ha}^{-1} \mathrm{em}$ cobertura, trigo, Urochloa ruziziensis e Crotalaria spectabilis. Nas subparcelas foram alocados duas adubações de $\mathrm{N}$ na implantação da soja (0 e $30 \mathrm{~kg}$ de $\mathrm{N}$ ha ${ }^{-1}$ ). De abril de 2016 a fevereiro de 2017 foram realizadas 26 coletas de solo na camada de 0,0-0,1 m, sendo avaliados os teores de nitrato e amônio nas amostras. Durante o período de entressafra da soja, os maiores teores de nitrato no solo foram observados no milho segunda safra adubado com $80 \mathrm{~kg} \mathrm{de} \mathrm{N} \mathrm{ha}^{-1}$, enquanto os teores de amônio variaram menos entre os tratamentos de entressafra. As culturas de entressafra não influenciaram os teores de nitrato e amônio no solo durante o ciclo da soja em sucessão. Na fase vegetativa da soja, os teores de nitrato no solo foram

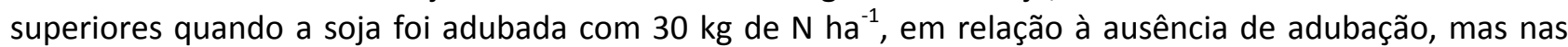
fases de formação de vagens e de grãos essa diferença não ocorreu.

Palavras-chave: culturas de cobertura; Glycine max L.; manejo do solo; nitrogênio inorgânico no solo; sistema plantio direto.
\end{abstract}

Nitrate and ammonium content in the soil as a function of off-season crops and nitrogen fertilization in the soybean

\begin{abstract}
The objective of this work was to evaluate the effect of off-season crops and fertilization with $\mathrm{N}$ mineral at soybean sowing on the nitrate and ammonium contents in the soil during the off-season and soybean development cycle. The experimental design was of randomized complete blocks, with five replications and in split plod scheme. Six off-season treatments were evaluated in the plots: fallow, maize with 0 or $80 \mathrm{~kg}$ of $\mathrm{N}$ ha ${ }^{1}$, wheat, Urochloa ruziziensis and Crotalaria spectabilis. In the subplots two levels of $\mathrm{N}$ were evaluated in the soybean sowing ( 0 and $30 \mathrm{~kg} \mathrm{~N} \mathrm{ha}^{-1}$ ). From April 2016 to February 2017, 26 soil samples were collected in the 0.0-0.1 m layer, and the nitrate and ammonium contents in the samples were evaluated. During the off-season, the highest contents of nitrate were observed in maize fertilized with 80 $\mathrm{kg}$ de $\mathrm{N} \mathrm{ha}^{-1}$, while ammonium contents varied less among off-season crops. The off-season crops did not influence the soil nitrate and ammonium content during the soybean cycle. In the vegetative phase of soybean, nitrate contents were higher when the soybean received nitrogen fertilization in relation to the absence of fertilization, but in the pod and grain formation there was no effect of the nitrogen fertilization on the contents of inorganic $\mathrm{N}$.
\end{abstract}

Keywords: cover crops; Glycine max L.; soil management; inorganic nitrogen in the soil; no-tillage system. 


\section{Introdução}

Na safra 2018/19, a soja ocupou cerca de 35,7 milhões de hectares no Brasil, sendo a cultura mais importante do agronegócio brasileiro, porém a cultura mais associada à soja no país é o milho safrinha, com cerca de 11,5 milhões de hectares (CONAB, 2019). Diante disso, a sucessão soja/milho safrinha intensifica o uso da terra, máquinas e mão de obra, no entanto quando utilizada por várias safras consecutivas, tem provocado redução da qualidade $\mathrm{e}$ conservação do solo e no aumento de problemas fitossanitários, como plantas daninhas de difícil controle, alguns insetos-praga, doenças necrotróficas e fitonematoides (DEBIASI et al., 2017).

Outra cultura usada na entressafra da soja é o trigo, especialmente em regiões subtropicais ou tropicais com altitudes superiores a $600 \mathrm{~m}$. As culturas de cobertura do solo também são alternativas para o cultivo na entressafra, como as braquiárias (LOSS et al., 2011) e as crotalárias (CARVALHO et al., 2013), objetivando melhorar a qualidade do solo e reduzir problemas fitossanitários. Adicionalmente, em várias regiões do país há ausência de cultivo na entressafra da soja (pousio), provocando aumento da erosão, da degradação da qualidade do solo e da ocorrência de plantas daninhas de difícil controle (MORAES et al., 2013; YOKOYAMA et al., 2018).

Os diferentes padrões de crescimento e requerimento de $\mathrm{N}$ das culturas de entressafra, bem como a produção de resíduos culturais em distintas quantidades e características químicas, como relação carbono/nitrogênio $(\mathrm{C} / \mathrm{N})$, podem influenciar os processos de ciclagem, imobilização e mineralização de $\mathrm{N}$ durante $\mathrm{o}$ ciclo dessas culturas ou na soja em sucessão (AULAKH et al., 2000). Nesse sentido, as culturas de entressafra podem afetar os teores de nitrato $\left(\mathrm{NO}_{3}{ }^{-}\right)$e amônio $\left(\mathrm{NH}_{4}{ }^{+}\right)$no solo (MORO et al., 2013). A palha com elevada relação $\mathrm{C} / \mathrm{N}$, como a produzida por milho, trigo e braquiária, pode imobilizar temporariamente $\mathrm{o} N$ presente na solução do solo, sobretudo na camada superficial, reduzindo momentaneamente o suprimento desse nutriente à cultura semeada em sucessão (LAMMEL et al., 2017).
A cultura da soja apresenta elevada demanda por $\mathrm{N}$, em função do elevado teor proteico da biomassa (BOHRER; HUNGRIA, 1998; SINCLAIR et al., 2003; SATURNO et al., 2017). Estima-se que sejam necessários cerca de $80 \mathrm{~kg}$ de $\mathrm{N}$ para a produção de $1.000 \mathrm{~kg}$ de grãos de soja (HUNGRIA et al., 2001). A demanda de $N$ pela soja pode ser atendida pela mineralização da matéria orgânica, pela fixação simbiótica e pela adubação (HUNGRIA et al., 2006). Assim, outro fator que pode alterar os teores de $\mathrm{N}$ inorgânico no solo é a adubação nitrogenada na soja, que, apesar de não ser indicada pela pesquisa, alguns produtores adotam (SATURNO et al., 2017). Uma das justificativas para uso de tal técnica é de que pode haver imobilização temporária de $\mathrm{N}$ pela palha em decomposição, especialmente de gramíneas, reduzindo os teores de $\mathrm{N}$ inorgânico no solo no início do ciclo da soja. Salienta-se que os efeitos da interação de culturas de entressafra e a adubação nitrogenada na soja sobre os teores de nitrato e amônio no solo ainda não foram adequadamente elucidados.

O objetivo desse trabalho foi avaliar os teores de nitrato e amônio no solo na entressafra e na safra de soja em função de culturas de entressafra e fertilização com $\mathrm{N}$ mineral na soja.

\section{Material e Métodos}

O experimento foi conduzido de março de 2016 a março de 2017, na Fazenda Experimental da Embrapa Soja, Londrina, PR (2311'37"S 51이'03"W, altitude de $630 \mathrm{~m}$ ). De acordo com a classificação de Köeppen, a região apresenta clima Cfa - subtropical, com temperatura média no mês mais frio inferior a $18^{\circ} \mathrm{C}$ (mesotérmico) e temperatura média no mês mais quente acima de $22^{\circ} \mathrm{C}$, verões quentes, geadas pouco frequentes e tendência de concentração das chuvas nos meses de verão, contudo sem estação seca definida (CAVIGLIONE et al., 2000). Os dados de precipitação pluvial e temperatura no período experimental (Figura 1) foram obtidos em estação meteorológica localizada a 500 metros do experimento. 
Figura 1. Precipitação pluvial por decêndio e temperaturas médias, máximas e mínimas do ar durante o período experimental - março de 2016 a março de 2017. Londrina, PR, 2016/17. Embrapa Soja.

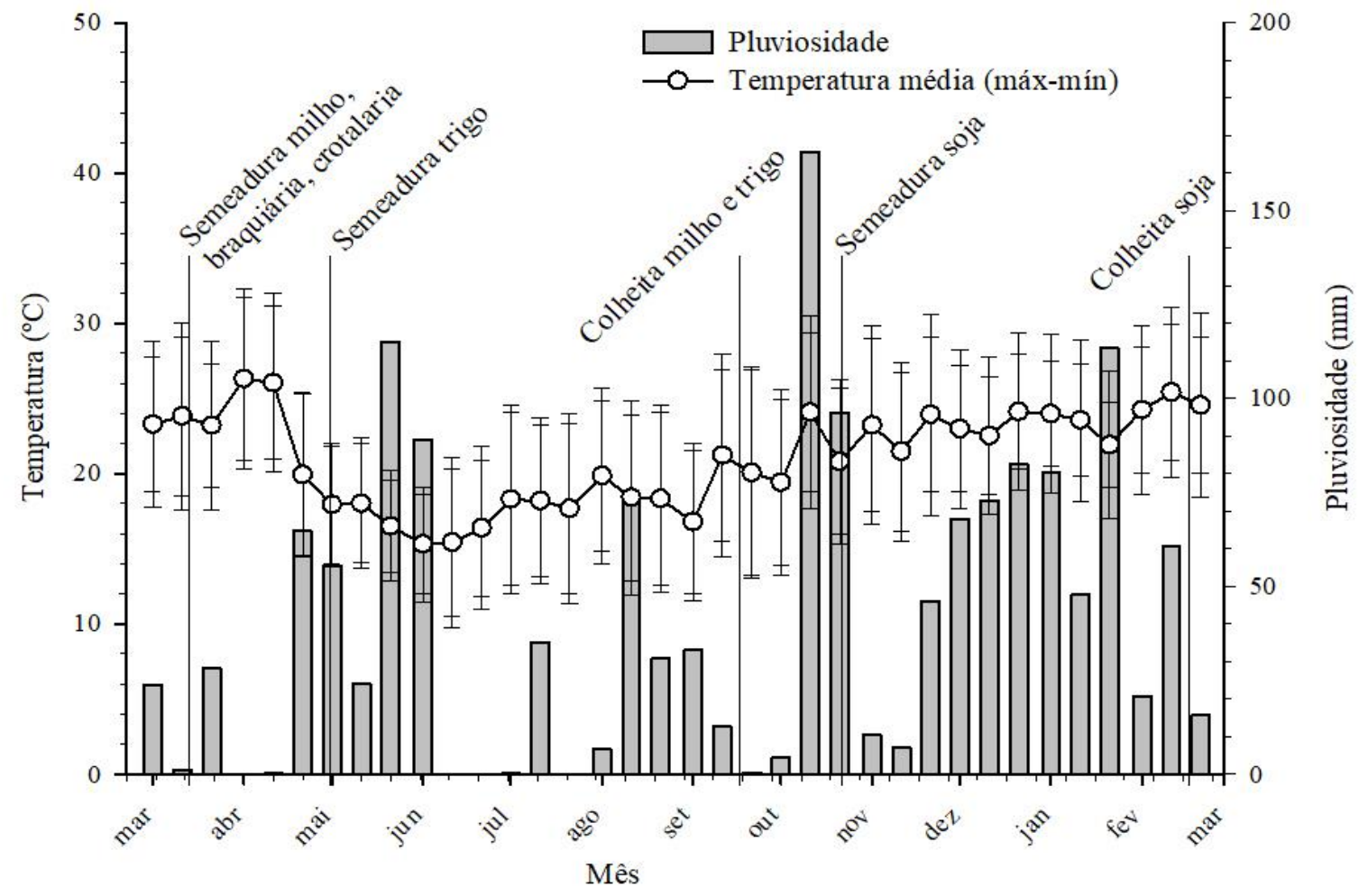


O solo da área experimental foi identificado como Latossolo Vermelho distroférrico (SANTOS et al., 2013), com os seguintes atributos físicos e químicos analisados na camada de 0-20 cm: 710, 82 e $208 \mathrm{~g} \mathrm{~kg}^{-1}$, de argila, silte e areia, C (Walkley Black) - 17,76 g dm 3; $\mathrm{pH}$ em $\mathrm{CaCl}_{2}$ 5,07; $\mathrm{H}^{+}+\mathrm{Al}^{3+}(\mathrm{SMP})-5,15 \mathrm{cmol}_{\mathrm{c}}$ $\mathrm{dm}^{-3} ; \mathrm{K}^{+}$(Mehlich-1) - 0,85 $\mathrm{cmol}_{\mathrm{c}} \mathrm{dm}^{-3} ; \mathrm{P}$ (Mehlich-1) - 36,95 mg dm${ }^{-3} ; \mathrm{Ca}^{2+}(\mathrm{KCl})-1,52$ $\mathrm{cmol}_{\mathrm{c}} \mathrm{dm}^{-3}$ e $\mathrm{Mg}^{2+}(\mathrm{KCl})-1,52 \mathrm{cmol}_{\mathrm{c}} \mathrm{dm}^{-3}$ (SILVA, 2009).

O delineamento experimental foi de blocos ao acaso, com cinco repetições e em parcelas subdividas. Nas parcelas principais $(5,0 \mathrm{x}$ $8,0 \mathrm{~m}$ ), foram dispostas seis formas de uso do solo na entressafra: pousio, milho safrinha com 0 ou $80 \mathrm{~kg}$ de $\mathrm{N} \mathrm{ha}^{-1}$ em cobertura, trigo, Urochloa ruziziensis e Crotalaria spectabilis, sendo as duas últimas destinadas à cobertura do solo. Nas subparcelas $(2,5 \times 8,0 \mathrm{~m})$ foram alocados dois níveis de adubação nitrogenada mineral na implantação da soja (0 e $30 \mathrm{~kg}$ de $\mathrm{N} \mathrm{ha}^{-1}$ ), a qual foi realizada em nitrato de amônio ( $34 \%$ de $N$ ).

A semeadura das culturas do milho, $U$. ruziziensis e $C$. spectabilis foram realizadas em 11 de março de 2016 e o trigo em 27 de abril de 2016. O milho (híbrido AG 9010 YG) foi semeado em espaçamento entre linhas de $0,90 \mathrm{~m}$ e 6 sementes $\mathrm{m}^{-1}$, obtendo-se 65 mil plantas ha ${ }^{-1}$. A braquiária, a crotalária e o trigo (cultivar BRS Gralha Azul) foram semeados em espaçamento de $0,17 \mathrm{~m}$, com 50,40 e 60 sementes $\mathrm{m}^{-1}$, respectivamente. A adubação de base para 0 milho e o trigo foi de 260 e $300 \mathrm{~kg} \mathrm{ha}^{-1}$, respectivamente, de fertilizante NPK 08-28-16. No trigo não foi utilizada adubação nitrogenada de cobertura, bem como não foi realizada fertilização de base ou cobertura na braquiária e na crotalária.

A fonte utilizada para o fornecimento de $N$ foi a ureia $(45 \% N)$ em cobertura no milho segunda safra, aplicada quando a cultura apresentava-se com seis folhas expandidas. No tratamento pousio, houve emergência espontânea de algumas plantas daninhas, principalmente buva (Conyza spp.) e capimamargoso (Digitaria insularis), em densidade inferior a 2 plantas $\mathrm{m}^{2}$. A colheita do milho e do trigo foi realizada no dia 15 de setembro de 2016. A área foi dessecada com glyphosate (1.080 g e.a. ha $^{-1}$ ) no dia 3 de outubro de 2016.

A soja, cultivar indeterminada BRS 1010 IPRO, que apresenta grau de maturidade 6.1, foi semeada no dia 16 outubro de 2016, em espaçamento de $0,45 \mathrm{~m}$ e na densidade de 16 sementes viáveis $\mathrm{m}^{-1}$. As sementes foram tratadas com Standak Top $\left(1 \mathrm{~mL} \mathrm{~kg}{ }^{-1}\right.$ de sementes) e inoculante líquido Gelfix $5^{\circ}$ contendo Bradyrhizobium elkaniibr ( $2 \mathrm{~mL} \mathrm{~kg}^{-1}$ de sementes). Foram utilizados $350 \mathrm{~kg} \mathrm{ha}^{-1}$ do adubo formulado 00-20-20.

As amostragens de solo foram realizadas de abril de 2016 até meados de fevereiro de 2017, totalizando 26 coletas. As primeiras 16 coletas foram realizadas antes da semeadura da soja, portanto consideraram apenas as parcelas, com as culturas de entressafra. As 10 coletas posteriores, realizadas durante o ciclo da soja, foram feitas nas subparcelas, considerando os dois níveis de adubação nitrogenada na soja.

No momento da coleta de solo, o material orgânico presente na superfície foi retirado manualmente. A amostragem foi realizada na camada de 0,0-0,1 $\mathrm{m}$, com trado calador na área útil de cada subparcela, obtendose uma amostra composta, com aproximadamente $0,5 \mathrm{~kg}$, oriunda de cinco sub amostras coletadas nas entrelinhas. Os teores de nitrato e amônio foram determinados por meio de extração com sulfato de potássio $\left(0,5 \mathrm{~mol} \mathrm{~L}^{-1}\right)$ e por colorimetria em espectrofotômetro (SEARLE, 1984), modelo Lambda-25 UV-Vis. Os teores de nitrato respondem na faixa de $220 \mathrm{~nm}$ e de $275 \mathrm{~nm}$, enquanto que os de amônio na faixa de $697 \mathrm{~nm}$ (SEARLE, 1984).

Os dados foram submetidos à análise de variância e teste $F(p \leq 0,05)$ e, quando constatado efeito significativo dos tratamentos, as médias foram comparadas por teste de Tukey, separadamente em cada coleta $(p \leq 0,05)$.

\section{Resultados e Discussão}

Durante o período de entressafra, das 16 coletas realizadas, houve diferença no teor de nitrato entre os tratamentos em 5 coletas (Tabela 1). Na coleta de $19 / 05$, o milho com nitrogênio apresentou teor superior de nitrato em relação à braquiária. No entanto, na coleta de 14/06 o teor de nitrato foi maior no milho com $\mathrm{N}$, comparativamente ao pousio e ao trigo. Nas coletas realizadas em $11 / 08$ e 24/08, constataram-se maiores teores de nitrato no solo no milho com $\mathrm{N}$ em relação ao trigo e à braquiária. Já, na coleta de 26/09 o milho com $\mathrm{N}$ obteve maior teor de nitrato em relação ao pousio e ao trigo.

Em relação aos teores de amônio no solo, das 16 coletas realizadas na entressafra, 
contatou-se diferença entre os tratamentos em apenas uma coleta, realizada em 19/05. Nesta, o teor de amônio foi maior no milho adubado com $\mathrm{N}$ quando comparado ao pousio, trigo $\mathrm{e}$ braquiária.

Com os resultados obtidos neste trabalho, pode-se inferir que o efeito dos tratamentos de entressafra foi mais acentuado nos teores de nitrato do que nos teores de amônio, sendo que a adubação com $80 \mathrm{~kg}$ de $\mathrm{N}$ ha $^{-1}$ no milho segunda safra teve incremento positivo nos teores de nitrato até o final de setembro, aproximadamente cinco meses após a adubação nitrogenada de cobertura e há menos de um mês da semeadura da soja em sucessão. De modo geral, o trigo e a braquiária apresentaram menores teores de nitrato no solo na entressafra, provavelmente em razão da absorção desse nutriente pelas plantas. Além disso, os menores teores de nitrato na braquiária, ao longo das coletas, podem ser justificados pela capacidade da planta em sintetizar inibidor biológico da nitrificação, denominado de brachialactone. Segundo Subbarao et al. (2015), a brachialactone age inibindo a atividade das enzimas nitrificadoras, que são responsáveis por transformar o amônio em nitrato no solo. Adicionalmente, a leguminosa utilizada no experimento (Crotalaria spectabilis) teve pouco impacto sobre os teores de $\mathrm{N}$ inorgânico no solo. Provavelmente isso ocorreu porque em junho de 2016 ocorreu forte geada na área experimental, provocando a morte das plantas dessa espécie. 
Tabela 1. Teores de nitrato $\left(\mathrm{N}^{-} \mathrm{NO}_{3}{ }^{-}\right)$e amônio $\left(\mathrm{N}-\mathrm{NH}_{4}{ }^{+}\right)$na camada de $0,0-0,10 \mathrm{~m}$ de solo, em 16 coletas, realizadas de abril de 2016 a outubro de 2016 , em função de seis culturas de entressafra da soja. Londrina, PR, 2016/17.

\begin{tabular}{|c|c|c|c|c|c|c|c|c|c|c|c|c|c|c|c|c|}
\hline & \multicolumn{16}{|c|}{ Datas de coleta } \\
\hline & $19 / 04$ & 02/05 & $19 / 05$ & 01/06 & $14 / 06$ & $27 / 06$ & $08 / 07$ & $19 / 07$ & 01/08 & $11 / 08$ & $24 / 08$ & 05/09 & $15 / 09$ & $26 / 09$ & $06 / 10$ & $16 / 10$ \\
\hline & \multicolumn{16}{|c|}{ Nitrato $-\mathrm{NO}_{3}^{-}\left(\mathrm{mg} \mathrm{kg}^{-1}\right)$} \\
\hline Pousio & 16,5 & 19,6 & $8,6 a b$ & 9,9 & $11,9 b$ & 10,3 & 12,4 & 13,0 & 9,6 & $6,3 a b$ & $5,4 a b$ & 12,1 & 13,8 & $15,5 b$ & 13,2 & 8,9 \\
\hline Milho SN & 13,2 & 19,6 & $8,6 a b$ & 9,8 & $15,0 \mathrm{ab}$ & 12,3 & 10,7 & 12,8 & 11,8 & $8,8 a$ & $6,5 a b$ & 15,6 & 15,6 & $15,6 a b$ & 14,9 & 11,3 \\
\hline Milho CN & 20,1 & 24,1 & $13,8 a$ & 11,5 & $22,1 \mathrm{a}$ & 13,4 & 20,0 & 13,2 & 15,9 & $10,2 a$ & $6,9 a$ & 18,5 & 19,7 & $20,8 a$ & 17,6 & 10,9 \\
\hline Trigo & 17,6 & 25,2 & $10,9 a b$ & 9,3 & $12,9 b$ & 9,6 & 8,7 & 9,4 & 8,3 & $2,1 b$ & $2,8 b$ & 13,8 & 14,5 & $15,2 b$ & 12,3 & 10,4 \\
\hline Braquiária & 13,9 & 17,4 & $7,4 b$ & 7,4 & $14,8 \mathrm{ab}$ & 11,2 & 12,3 & 10,6 & 11,0 & $2,8 b$ & $2,7 b$ & 15,8 & 16,3 & $16,7 a b$ & 15,6 & 12,3 \\
\hline Crotalária & 12,2 & 18,4 & $9,2 a b$ & 9,8 & $15,0 \mathrm{ab}$ & 13,3 & 14,0 & 13,4 & 12,0 & $7,7 a b$ & $6,7 a b$ & 18,1 & 16,9 & $15,8 \mathrm{ab}$ & 14,7 & 11,2 \\
\hline \multirow[t]{2}{*}{ C.V.(\%) } & 35,4 & 16,6 & 31,3 & 20,0 & 26,3 & 29,4 & 42,7 & 21,7 & 38,6 & 47,5 & 39,5 & 50,6 & 23,8 & 16,1 & 19,4 & 25,9 \\
\hline & \multicolumn{16}{|c|}{ Amônio - $\mathrm{NH}_{4}{ }^{+}\left(\mathrm{mg} \mathrm{kg}^{-1}\right)$} \\
\hline Pousio & 13,6 & 12,6 & $3,2 b$ & 2,7 & 11,7 & 5,6 & 4,0 & 3,7 & 5,5 & 1,8 & 1,8 & 2,0 & 8,0 & 3,7 & 14,3 & 19,1 \\
\hline Milho SN & 10,2 & 11,9 & $3,4 a b$ & 2,7 & 11,0 & 3,1 & 3,5 & 3,3 & 5,3 & 1,5 & 1,2 & 1,6 & 9,0 & 3,9 & 16,1 & 27,0 \\
\hline Milho CN & 16,1 & 18,1 & $4,2 a$ & 6,1 & 5,5 & 4,0 & 8,6 & 6,5 & 6,8 & 1,6 & 1,7 & 1,9 & 8,4 & 4,1 & 10,8 & 24,2 \\
\hline Trigo & 11,3 & 15,4 & $3,1 b$ & 2,5 & 9,1 & 6,3 & 6,6 & 6,1 & 9,3 & 1,6 & 1,7 & 1,9 & 9,0 & 3,9 & 13,9 & 19,0 \\
\hline Braquiária & 12,9 & 11,5 & $3,0 b$ & 3,1 & 9,7 & 5,3 & 8,2 & 4,3 & 8,0 & 1,5 & 1,3 & 1,8 & 10,0 & 4,1 & 20,2 & 23,4 \\
\hline Crotalária & 12,8 & 13,4 & $3,9 a b$ & 2,7 & 9,6 & 4,4 & 7,6 & 6,0 & 5,1 & 2,0 & 1,5 & 1,7 & 8,8 & 4,1 & 21,6 & 18,9 \\
\hline C.V.(\%) & 31,0 & 32,6 & 14,0 & 67,6 & 47,2 & 70,7 & 53,9 & 72,3 & 39,6 & 28,8 & 44,2 & 39,0 & 18,3 & 14,8 & 55,1 & 35,3 \\
\hline
\end{tabular}

Médias seguidas pelas mesmas letras nas colunas não diferem entre si pelo teste Tukey $(p \leq 0,05)$. ns=não significativo. $\mathrm{SN}=$ sem nitrogênio. $\mathrm{CN}=\mathrm{com} 80 \mathrm{~kg}$ de nitrogênio ha ${ }^{-1}$. 
No período de entressafra da soja, observou-se que os menores teores de nitrato e amônio no solo ocorreram quando houve associação de baixas temperaturas do ar com alta precipitação (Tabela 1 e Figura 1). Isso pode ser constatado nas coletas realizadas em 19/05, 01/06, 17/08 e 24/08. Possivelmente isso ocorreu porque as baixas temperaturas reduziram 0 processo de mineralização e as precipitações ocorridas podem ter movido o nitrato da camada superficial avaliada $(0,0-0,1 \mathrm{~m})$ para camadas subsuperficiais do solo. Solos corrigidos possuem coloides com cargas predominantemente negativas, que repulsam as cargas aniônicas (CRUSCIOL et al., 2011), favorecendo a percolação e o movimento descendente do nitrato. Nesse contexto, a associação de baixas temperaturas com alta precipitação pode reduzir o teor de nitrato no solo (ROSOLEM et al., 2003; DARYANTO et al., 2018).

Durante o ciclo da soja, nas 10 coletas realizadas, não houve efeito da interação entre os tratamentos de entressafra e a adubação nitrogenada na soja sobre os teores de nitrato e amônio no solo, apesar das culturas de entressafra produzirem quantidades distintas de palha, com diferentes características químicas (YOKOYAMA et al., 2018). Na média das cinco repetições o milho sem e com adubação nitrogenada produziu 2,5 e $2,8 \mathrm{t} \mathrm{ha}^{-1}$ de palha, enquanto $\mathrm{o}$ trigo, a braquiária e a crotalária produziram 4,$7 ; 3,5$ e $0,3 \mathrm{t} \mathrm{ha}^{-1}$ de palha, respectivamente.

Os tratamentos de entressafra não influenciaram os teores de nitrato e amônio no solo durante o cultivo da soja em sucessão (Tabela 2). Assim, para esse trabalho não confirmou-se a hipótese de que a decomposição da palha de espécies de gramíneas, como milho, trigo e braquiária reduzem os teores de $\mathrm{N}$ inorgânico em relação ao pousio ou com cultivo de crotalária. Em trabalho desenvolvido por Moro et al. (2013) também constatou-se que o cultivo de Crotalaria spectabilis não proporcionou aumento nos teores de nitrato e amônio no solo até $0,2 \mathrm{~m}$ de profundidade, em relação ao cultivo de quatro espécies de braquiária (Urochloa ruziziensis, $U$. brizantha, $U$. humidicola e $U$. decumbens). 
Tabela 2. Teores de nitrato $\left({\mathrm{N}-N \mathrm{NO}_{3}}^{-}\right)$e amônio $\left(\mathrm{N}^{-\mathrm{NH}_{4}}{ }^{+}\right)$na camada de $0,0-0,10 \mathrm{~m}$ de solo, em 10 coletas, realizadas de outubro de 2016 a fevereiro de 2017 , em função de seis culturas de entressafra da soja e adubação nitrogenada mineral na soja. Londrina, PR, 2016/17.

Datas de coleta e estádios de desenvolvimento da soja
$\begin{array}{llllllllll}28 / 10 & 08 / 11 & 21 / 11 & 02 / 12 & 13 / 12 & 23 / 12 & 03 / 01 & 20 / 01 & 30 / 01 & 15 / 02 \\ \text { (V1) } & \text { (V3) } & \text { (R1) } & \text { (R3) } & \text { (R4) } & \text { (R5.1) } & \text { (R5.3) } & \text { (R5.4) } & \text { (R6) } & \text { (R7) }\end{array}$

Nitrato $-\mathrm{NO}_{3}^{-}\left(\mathrm{mg} \mathrm{kg}^{-1}\right)$

\begin{tabular}{|c|c|c|c|c|c|c|c|c|c|c|}
\hline Pousio & 14,4 & 15,4 & 13,7 & 15,4 & 14,2 & 15,3 & 19,9 & 17,9 & 11,4 & 12,9 \\
\hline Milho SN & 13,8 & 16,9 & 8,5 & 17,4 & 16,2 & 19,4 & 18,9 & 17,0 & 11,4 & 15,6 \\
\hline Milho CN & 13,6 & 17,7 & 7,4 & 17,7 & 16,4 & 22,9 & 19,3 & 23,3 & 11,9 & 14,4 \\
\hline Trigo & 17,1 & 14,3 & 11,9 & 15,3 & 16,5 & 17,1 & 19,2 & 20,1 & 10,6 & 11,9 \\
\hline Braquiária & 13,9 & 16,9 & 11,5 & 19,2 & 14,7 & 18,5 & 18,1 & 15,7 & 12,5 & 13,9 \\
\hline Crotalária & 17,0 & 16,9 & 6,8 & 18,2 & 16,7 & 20,2 & 18,9 & 16,0 & 11,7 & 12,5 \\
\hline C.V.(\%) & 41 & 17 & 85 & 17 & 15 & 31 & 22 & 35 & 18 & 17 \\
\hline Soja SN & $13,5 b$ & $15,3 b$ & $8,2 b$ & 16,6 & 16,0 & 19,5 & 19,2 & 20,0 & 11,7 & 13,8 \\
\hline Soja CN & $16,4 a$ & $17,3 a$ & $11,8 \mathrm{a}$ & 17,8 & 15,6 & 18,3 & 18,9 & 16,7 & 11,4 & 13,3 \\
\hline C.V.(\%) & 45 & 15 & 67 & 16 & 20 & 43 & 17 & 34 & 13 & 18 \\
\hline Interação & ns & ns & ns & ns & ns & ns & ns & ns & ns & ns \\
\hline
\end{tabular}

Amônio - $\mathrm{NH}_{4}^{+}\left(\mathrm{mg} \mathrm{kg}^{-1}\right)$

$\begin{array}{lllllllllll}\text { Pousio } & 15,6 & 5,6 & 25,7 & 3,1 & 2,5 & 5,1 & 7,4 & 11,6 & 6,8 & 3,9 \\ \text { Milho SN } & 12,7 & 5,4 & 27,1 & 4,7 & 3,2 & 4,4 & 7,0 & 6,2 & 6,4 & 4,5 \\ \text { Milho CN } & 8,4 & 2,8 & 22,9 & 4,6 & 2,6 & 3,6 & 7,8 & 6,3 & 6,7 & 4,1 \\ \text { Trigo } & 5,8 & 6,4 & 25,6 & 4,4 & 4,2 & 4,7 & 6,9 & 6,1 & 5,9 & 4,0 \\ \text { Braquiária } & 10,3 & 12,1 & 20,1 & 4,4 & 8,0 & 4,8 & 6,5 & 9,9 & 6,1 & 5,1 \\ \text { Crotalária } & 14,2 & 11,1 & 23,9 & 2,6 & 2,6 & 5,5 & 6,5 & 8,0 & 6,5 & 3,9 \\ \text { C.V.(\%) } & 95 & 104 & 34 & 63 & 128 & 73 & 19 & 80 & 27 & 37 \\ \text { Soja SN } & 13,2 & 6,6 & 25,5 & 4,2 & 3,9 & 5,0 & 6,9 & 8,8 & 6,1 & 4,4 \\ \text { Soja CN } & 9,2 & 7,9 & 22,9 & 3,7 & 3,8 & 4,4 & 7,1 & 7,2 & 6,7 & 4,1 \\ \text { C.V.(\%) } & 70 & 82 & 28 & 50 & 59 & 62 & 24 & 43 & 27 & 47 \\ \text { Interação } & \text { ns } & \text { ns } & \text { ns } & \text { ns } & \text { ns } & \text { ns } & \text { ns } & \text { ns } & \text { ns } & \text { ns }\end{array}$

Médias seguidas pelas mesmas letras nas colunas não diferem entre si pelo teste Tukey $(p \leq 0,05)$. ns=não significativo. SN=sem nitrogênio. $\mathrm{CN}=\mathrm{com}^{80} \mathrm{~kg}$ de nitrogênio ha ${ }^{-1} \mathrm{em}$ cobertura no milho ou com $30 \mathrm{~kg}$ de $\mathrm{N}$ ha ${ }^{-1}$ na semeadura da soja. 
A adubação na implantação da soja com $30 \mathrm{~kg}$ de $\mathrm{N} \mathrm{ha}^{-1}$ aumentou os teores de nitrato no solo nas três coletas realizadas após a semeadura da cultura, período que transcorre da emergência ao início de florescimento da cultura. Após o dia 02/12, a adubação nitrogenada na soja não influenciou os teores de nitrato no solo. Por outro lado, os teores de amônio não foram influenciados pela adubação nitrogenada na soja. Na presente pesquisa, as culturas de entressafra e a adubação nitrogenada na soja não influenciaram a produtividade de grãos - média de $4,4 \mathrm{t} \mathrm{ha}^{-1}$ (YOKOYAMA et al., 2018). Isso demonstra que $o$ aumento no teor de nitrato no início do ciclo, proporcionado pela adubação nitrogenada, não impacta na produtividade da soja, corroborando vários resultados de pesquisa (FRANCHINI et al., 2015; FERREIRA et al., 2016; WERNER et al., 2016; SATURNO et al., 2017; MOURTZINIS et al., 2018).

Durante o ciclo da soja, as temperaturas mínimas e máximas médias diárias variaram de 17 a $31{ }^{\circ} \mathrm{C}$, sem ocorrência de déficit hídrico (Figura 1). Nesse período, os teores de nitrato no solo não variaram acentuadamente entre as 10 coletas realizadas (Tabela 2). No entanto, os teores de amônio variaram expressivamente entre as coletas durante o ciclo da soja. Por exemplo, a média de teor de amônio caiu de 24,2 $\mathrm{mg} \mathrm{kg}^{-1}$ na coleta realizada em $21 / 11$ para apenas $4,0 \mathrm{mg} \mathrm{kg}^{-1} \mathrm{em} \mathrm{02/12}$. Isso demonstra a grande variação temporal do teor de amônio no solo.

De forma geral, considerando a entressafra e a safra da soja os teores de nitrato e amônio no solo variaram expressivamente no tempo. $\mathrm{O}$ grande número de reações do $\mathrm{N}$ no solo e a predominância da forma nítrica (AULAKH et al., 2000) fazem com que os valores de $\mathrm{N}$ mineral no solo variem amplamente, mesmo no período de poucos dias (MORO et al., 2013), o que dificulta a utilização de análises laboratoriais de rotina para estimar sua disponibilidade às culturas (ERNANI et al., 2002). Além disso, é necessário considerar a grande variabilidade espacial dos teores de nitrato e amônio no solo, que podem variar consideravelmente em curtas distâncias (ROSOLEM et al., 2003).

\section{CONCLUSÕES}

O milho safrinha adubado com $80 \mathrm{~kg}$ de $\mathrm{N}$ $\mathrm{ha}^{-1}$ apresentou maior teor de nitrato no solo durante a entressafra, no entanto houve pouca variação nos teores de amônio entre os tratamentos.
As culturas de entressafra não influenciaram os teores de nitrato e amônio no solo durante a soja em sucessão.

$\mathrm{Na}$ fase vegetativa da soja, os teores de nitrato no solo foram superiores quando a soja foi adubada com $30 \mathrm{~kg}$ de $\mathrm{N}$ ha ${ }^{-1}$, em relação à ausência de adubação, mas na fase reprodutiva essa diferença não ocorreu.

\section{AGRADECIMENTOS}

A Coordenação de Aperfeiçoamento de Pessoal de Nível Superior (Capes) pela concessão de bolsa de mestrado para Anderson Hideo Yokoyama e ao Conselho Nacional de Desenvolvimento Científico e Tecnológico pela bolsa de produtividade em Desenvolvimento Tecnológico e Extensão Inovadora 1D para Alvadi Antonio Balbinot Junior.

\section{REFERÊNCIAS}

AULAKH, M.S.; KHERA, T.S.; DORAN, J.W.; SINGH, K.; SINGH, B. Yields and nitrogen dynamics in a rice-wheat system using green manure and inorganic fertilizer. Soil Science Society of America Journal, v.64, n.5, p.1867-1876, 2000. http://dx.doi.org/10.2136/sssaj2000.6451867x

BOHRER, T.R.J.; HUNGRIA, M. Avaliação de cultivares de soja quanto à fixação biológica do nitrogênio. Pesquisa Agropecuária Brasileira, v.33, n.6, p. 937-952, 1998.

CARVALHO, W.P.; CARVALHO, G.J.; NETO, D.O.A.; TEIXEIRA, L.G.V. Desempenho agronômico de plantas de cobertura usadas na proteção do solo no período de pousio. Pesquisa Agropecuária Brasileira, v.48, n.2, p.157-166, 2013. http://dx.doi.org/10.1590/s0100-

204X2013000200005

CAVIGLIONE, J.H.; KIIHL, L.R.B.; CARAMORI, P.H.; OLIVEIRA, D.; GALDINO, J.; BORROZINO, E.; PUGSLEY, L. Cartas climáticas do Estado do Paraná. Londrina: IAPAR, 2000. CD- ROM.

CONAB. Acompanhamento da safra brasileira de grãos. 2019. Disponível em: https://www.conab.gov.br/index.php/infoagro/safras/graos. Acesso em: 04 jan. 2019.

CRUSCIOL, C.A.C.; GARCIA, R.A.; CASTRO, G.S.A.; ROSOLEM, C.A. Nitrate role in basic cation leaching under no-till. Revista Brasileira de Ciência do Solo, v.35, n.6 p.1975-1984, 2011. 
http://dx.doi.org/10.1590/S0100-

\section{$\underline{06832011000600014}$}

DARYANTO, S.; WANG, L.; GILHOOLY, W.P.; JACINTHE, P.A. Nitrogen preference across generations under changing ammonium nitrate ratios. Journal of Plant Ecology, p.014, 2018. https://doi.org/10.1093/ipe/rty014

DEBIASI, H.; FRANCHINI, J. C.; BALBINOT JUNIOR, A.A.; BETIOLI JUNIOR, E.; NUNES, E.S.; FURLANETTO, R.H.; MENDES, M.R.P. Alternativas para diversificação de sistemas de produção envolvendo a soja no norte do Paraná. Londrina: Embrapa, 2017.

ERNANI, P.R.; SANGOI, L.; RAMPAZZO, C. Lixiviação e imobilização de nitrogênio num Nitossolo como variáveis da forma de aplicação da ureia e da palha de aveia. Revista Brasileira de Ciência do Solo, v.26, n.4, p.993-1000, 2002. http://dx.doi.org/10.1590/S0100-

$\underline{06832002000400017}$

FERREIRA, A.S.; BALBINOT JUNIOR, A.A. ; WERNER, F.; ZUCARELI, C.; FRANCHINI, J.C.; DEBIASI, $\mathrm{H}$. Plant density and mineral nitrogen fertilization influencing yield, yield components and concentration of oil and protein in soybean grains. Bragantia, v.75, n.3, p.1, 2016. http://dx.doi.org/10.1590/1678-4499.479

FRANCHINI, J.C.; BALBINOT JUNIOR, A.A.; DEBIASI, H.; CONTE, O. Desempenho da soja em consequência de manejo de pastagem, época de dessecação e adubação nitrogenada. Pesquisa Agropecuária Brasileira, v.50, n.12, p.1131-1138, $2015 . \quad$ http://dx.doi.org/10.1590/S0100204X2015001200002

HUNGRIA, M.; CAMPO, J.R.; MENDES, I.C. Fixação biológica do nitrogênio na cultura da soja. Londrina: EMBRAPA, 2001. 48 p.

HUNGRIA, M.; FRANCHINI, J.C.; CAMPO, R.J.; CRISPINO, C.C.; MORAES, J.Z.; SIBALDELLI, R.N.R.; MENDES, I.C.; ARIHARA, J. Nitrogen nutrition of soybean in Brazil: Contributions of biological N2 fixation and $\mathrm{N}$ fertilizer to grain yield. Canadian Journal of Plant Science, v.86, n.4, p.927-939, 2006. https://doi.org/10.4141/P05-098

LAMMEL, D.R.; BUTTERBACH-BAHL, K.; CERRI, C.E.P.; LOUIS, S.; SCHNITZLER, J.; FEIGL, B.J.;
LOSS, A.; PEREIRA, M.G.; GIÁCOMO, S.G.; PERIN, A.; ANJOS, L.H.C. Agregação, carbono e nitrogênio em agregados do solo sob plantio direto com integração lavoura-pecuária. Pesquisa Agropecuária Brasileira, v.46, n.10, p.1269-1276, $2011 . \quad$ http://dx.doi.org/10.1590/S0100$\underline{204 \times 2011001000022}$

MORAES, P.V.D.; AGOSTINETTO, D.; PANOZZO, L.; OLIVEIRA, C.E.; VIGNOLO, G.K.; MARKUS, C. Manejo de plantas de cobertura no controle de plantas daninhas e desempenho produtivo da cultura do milho. Semina: Ciências Agrárias, v.34, n.2, p.497-508, 2013. http://dx.doi.org/10.1590/S0100-

83582009000200011

MORO, E.; CRUSCIOL, C.A.C.; NASCENTE, A.S.; CANTARELLA, H. Teor de nitrogênio inorgânico no solo em função de plantas de cobertura, fontes de nitrogênio e inibidor de nitrificação. Pesquisa Agropecuária Tropical, v.43, n.4, p.424-435, 2013.

MOURTZINIS, S.; KAUR, G.; ORLOWSKI, J.M.; SHAPIRO, C.A.; LEE, C.D.; WORTMANN, C.; HOLSHOUSER, D.; NAFZIGER, E.D.; KANDEL, H.; NIEKAMP, J.; ROSS, W.J.; LOFTON, J.; VONK, J.; ROOZEBOOM, K.L.; THELEN, K.D.; LINDSEY, L.E.; STATON, M.; NAEVE, S.L.; CASTEEL, S.N.; WIEBOLD, W.J.; CONLEY, S.P. Soybean response to nitrogen application across the United States: A synthesis-analysis. Field Crops Research, v.215, p.74-82, 2018. https://doi.org/10.1016/j.fcr.2017.09.035

SANTOS, H. G.; JACOMINE, P. K. T.; ANJOS, L. H. C. DOS; OLIVEIRA, V. A.; OLIVEIRA, J. B.; COELHO, M. R.; LUMBRERAS, J. F.; CUNHA, T. J. F. Sistema brasileiro de classificação de solos. 3. ed. Rio de Janeiro: Embrapa Solos, 2013. 306p.

SATURNO, D.F.; CEREZINI, P.; SILVA, P.M.; OLIVEIRA, A.B.; OLIVEIRA, M.C.N.; HUNGRIA, M.; NOGUEIRA, M.A. Mineral nitrogen impairs the biological nitrogen fixation in soybean of determinate and indeterminate growth types. Journal of Plant Nutrition, v.40, n.12, p.16901710, 2017. https://doi.org/10.1080/01904167.2017.1310890

SEARLE, P.L. The Berthelot or indophenol reaction and its use in the analytical chemistry of nitrogen. 
Analyst, v.109, p.549-568, 1984. https://doi.org/10.1039/AN9840900549

SILVA, F.C. Manual de análises químicas do solo, plantas e fertilizantes. 2. ed. Brasília: Embrapa Informação Tecnológica, 2009. 627p.

SINCLAIR, T.R.; FARIAS, J.R.; NEUMAIER, N.; NEPOMUCENO, A.L. Modeling nitrogen accumulation and use by soybean. Field Crops Research, v.81, n.2-3, p.149-158, 2003. https://doi.org/10.1016/S0378-4290(02)00221-6

SUBBARAO, G.V.; YOSHIHASHI, T.; WORTHINGTON, M.; NAKAHARA, K.; ANDO, Y.; SAHRAWAT, K.L.; RAO, I.M.; LATA, J.C.; KISHI, M.; BRAUN, H.J. Suppression of soil nitrification by plants. Plant Science, v.233, p.155-164, 2015. https://doi.org/10.1016/i.plantsci.2015.01.012

WERNER, F.; BALBINOT JR., A.A.; FERREIRA, A.S.; AGUIAR E SILVA, M.A.; DEBIASI, H.; FRANCHINI, J.C. Soybean growth affected by seeding rate and mineral nitrogen. Revista Brasileira de Engenharia Agrícola e Ambiental. v.20, n.8, p.734-738, 2016. http://dx.doi.org/10.1590/1807$\underline{1929 / a g r i a m b i . v 20 n 8 p 734-738}$

YOKOYAMA, A.H.; RIBEIRO, R.H.; BALBINOT JUNIOR, A.A.; FRANCHINI, J.C.; DEBIASI, H.; ZUCARELI, C. Índices de área foliar e SPAD da soja em função de culturas de entressafra e nitrogênio e sua relação com a produtividade. Revista de Ciências Agrárias, v.41, n.4, p.953-962, 2018. http://dx.doi.org/10.19084/RCA18153 